\title{
Effectiveness and safety of surgical interventions for treating adolescent idiopathic scoliosis: a Bayesian meta- analysis
}

Long Chen ${ }^{1 \dagger}$, Zeyu Sun ${ }^{1 \dagger}$, Jingming $\mathrm{He}^{1 \dagger}$, Yunwen Xu ${ }^{2}$, Zhuhai $\mathrm{Li}^{3}$, Qian Zou ${ }^{1}$ and Bo $\mathrm{Li}^{1^{*}}$

\begin{abstract}
Background: Adolescent idiopathic scoliosis (AIS) is the most common form of spinal deformity in children and adolescents which presents as complex three-dimensional (3D) deformity of the spine and rib cage. This study aimed to estimate the effectiveness and safety of surgical interventions for AIS using Bayesian meta-analysis.

Methods: The PubMed, EMBASE, and Cochrane Controlled Register of Trials were searched through Oct 1, 2019, without language restrictions. Relevant studies evaluating combined effectiveness and safety of surgical interventions for AIS were included according to eligibility criteria. The primary outcome measures included pulmonary function (change of absolute forced vital capacity and forced expiratory volume in 1 second from preoperation to post-operation) and incidence of complications. The secondary outcome measure was change of Cobb angle from pre-operation to post-operation. Data was pooled using a random effects model in pairwise meta-analysis. Bayesian meta-analysis combined direct and indirect evidence using a Bayesian framework.

Results: Twenty-eight case-controlled studies with totally 1970 participants were included. This Bayesian metaanalysis combining direct and indirect evidences indicated that posterior fusion with instrumentation without thoracoplasty (PSF) had the highest probability to achieve better pulmonary function and lower complication rate; video assisted anterior fusion with instrumentation without thoracoplasty (VAT) had the highest probability to obtain better Cobb angle correction based on analysis of rank probability.

Conclusion: This Bayesian meta-analysis demonstrated that PSF had the highest probability to achieve better postsurgical pulmonary function and lower complication rate, which gives a practical recommendation of PSF as a primary surgical treatment for AIS. The results also support statistics that current surgeries adopted more PSF but less open anterior approach surgery and thoracoplasty. More research work is required to address the effectiveness and safety of VAT for treating AIS more convincingly.
\end{abstract}

Keywords: Adolescent idiopathic scoliosis, Surgical interventions, Pulmonary function, Complications, Cobb angle, Bayesian meta-analysis

\footnotetext{
* Correspondence: libo8588@hotmail.com

${ }^{\dagger}$ Long Chen, Zeyu Sun and Jingming He contributed equally to this work.

'Department of Orthopedics, Guizhou Provincial People's Hospital, No.83

Zhongshan East Road, Guiyang 550000, Guizhou, China

Full list of author information is available at the end of the article
}

(c) The Author(s). 2020 Open Access This article is licensed under a Creative Commons Attribution 4.0 International License, which permits use, sharing, adaptation, distribution and reproduction in any medium or format, as long as you give appropriate credit to the original author(s) and the source, provide a link to the Creative Commons licence, and indicate if changes were made. The images or other third party material in this article are included in the article's Creative Commons licence, unless indicated otherwise in a credit line to the material. If material is not included in the article's Creative Commons licence and your intended use is not permitted by statutory regulation or exceeds the permitted use, you will need to obtain permission directly from the copyright holder. To view a copy of this licence, visit http://creativecommons.org/licenses/by/4.0/. The Creative Commons Public Domain Dedication waiver (http://creativecommons.org/publicdomain/zero/1.0/) applies to the data made available in this article, unless otherwise stated in a credit line to the data. 


\section{Background}

Adolescent idiopathic scoliosis (AIS) is the most common form of spinal deformity in children and adolescents which presents as complex three-dimensional (3D) deformity of the spine and rib cage [1-3]. Its prevalence is about $1-3 \%$ of adolescent aged 10 to 16 years old, with almost $10 \%$ and up to $0.1 \%$ of the patients having the necessity of treatment and surgery, respectively [4]. The diagnosis of AIS is traditionally based on Cobb method for evaluation of the spinal curvature. Patients are diagnosed as AIS when the Cobb angle $\geq 10^{\circ}$ [5]. Treatment strategies for AIS can be conservative or surgical. Conservative treatments including observation and brace treatment are always applied to patients with small and moderate curves or skeletal maturity, otherwise, surgical treatment would be recommended for those with severe curves [6].

Surgical interventions aim to terminate the progression of AIS, achieve maximum permanent correction of the 3D deformity, promote appearance by balancing the trunk, and keep lower incidence rate of short-term and long-term complications [7]. The surgery for AIS has been developed for one century since Hibbs first performed fusion procedure to treat AIS [8]. In 1953, Harrington introduced instrumentations to spinal fusions, which could improve the correction of deformity and decrease the pseudarthrosis rate [9]. The postoperative cast had been a routine procedure in use until Luque's sublaminar wiring was introduced to treat AIS in 1970s [10]. Although several methods were introduced, thoracotomy was still required before 2000 because of the rib prominence and coronal plane decompensation [4]. Then segmental hook instrumentation, segmental pedicle screw constructs and hybrid constructs (pedicle screws, hooks, and wires) were successively introduced to three dimensional correction for treating AIS [11]. Depending on specific conditions diagnosed in clinic, different surgical procedures are adopted. The posterior surgery technique was developed by Harrington in 1962, which have been improving with clinical practice till recently and become a widely used standard procedure for treating AIS $[12,13]$. Anterior surgery was reported by Dwyer et al. in 1974, which has been used commonly for thoracolumbar and lumbar curves [14]. In order to reduce the adverse effects for pulmonary function after open thoracotomy and anterior spinal fusion, thoracoscopic and video assisted procedures were developed for treating AIS [15]. As recently summarized by Lee et al. [16], the common surgical interventions for treating AIS were categorized as follows: combined anterior release and posterior fusion with instrumentation (ASR + PSF), combined video assisted anterior release and posterior fusion with instrumentation without thoracoplasty $(\mathrm{VAT}+\mathrm{PSF})$, posterior fusion with instrumentation without thoracoplasty (PSF), anterior fusion with instrumentation and thoracotomy without thoracoplasty (ASF), video assisted anterior fusion with instrumentation without thoracoplasty (VAT), and any scoliosis surgery with additional thoracoplasty or multiple convex rib resections (WT). To choose the safest and the most effective procedures has always been essential for patient treatments.

Several traditional pairwise meta-analyses of surgical interventions for treating AIS have been published previously $[2,13,16,17]$. The information provided by these studies is limited because the traditional pairwise metaanalysis is only capable of making comparison between two surgical interventions at a time, thus prone to result in a local optimum as the conclusion. To compare effectiveness and safety across multiple surgical interventions at a time, taking the advantages and disadvantages of all the procedures into consideration, would generate more comprehensive criterion for decision-making of the doctors. To achieve this, Bayesian meta-analysis was developed as an attractive evidence-based technique to compare the relative benefits of multiple interventions and obtain rank probability of these interventions [18], which have overcome the limitation of traditional pairwise meta-analysis. In contrary to traditional metaanalysis, in which only direct evidence is available, Bayesian meta-analysis could also incorporate indirect evidences among all interventions besides direct evidences to improve estimation precision.

The objective of this study is to compare the effectiveness and safety of ASR + PSF, VAT+PSF, PSF, ASF, VAT and WT for treating AIS via Bayesian meta-analyses regarding 4 criteria: Cobb angle, absolute forced vital capacity (FVC), absolute forced expiratory volume in 1 second (FEV1) and incidence of complications.

\section{Methods}

This Bayesian meta-analysis was performed according to Preferred Reporting Items for Systematic Reviews and Meta-Analyses (PRISMA) guidelines [19], and was also registered on PROSPERO (CDR 42018079968).

\section{Data sources and searches}

Databases including Cochrane Controlled Register of Trials, PubMed and EMBASE (Jan 1980 to Oct 2019) were used to identify all studies that evaluated the effectiveness and safety of surgical interventions for treating AIS, with the searching strategy being: (Adolescent idiopathic scoliosis) AND (surgery OR surgical intervention OR surgical treatment OR surgical management) AND (randomized controlled trials OR case-controlled trials). The titles and abstracts were screened by two independent reviewers to exclude any reports that did not assess the effectiveness and safety of surgical treatment for AIS. 
Full texts of the remaining articles were reviewed to identify studies that met inclusion criteria.

\section{Inclusion and exclusion criteria}

The inclusion criteria were: (1) target population: pediatric patients suffered from AIS; (2) interventions: $\mathrm{ASR}+\mathrm{PSF}, \mathrm{VAT}+\mathrm{PSF}, \mathrm{PSF}, \mathrm{ASF}, \mathrm{VAT}$ and WT for treating AIS; (3) methodological criteria: Controlled clinical trials.

The exclusion criteria were: (1) target population: patients with other type of scoliosis; (2) interventions: conservative treatments or surgical treatments except those that were above-mentioned; (3) methodological criteria: case series.

\section{Outcome assessment}

The primary outcome measures include pulmonary functions (change of absolute FVC and FEV1 from pre-operation to post-operation) and incidence of complications (including infection, hook and screw dislodgement, hemothorax, pleural effusion, neurological complications, vascular complications, etc.). The secondary outcome measure was change of Cobb angle from pre-operation to post-operation.

\section{Data extraction and assessment of risk of bias}

For each trial, we gathered data on study type, sample size, interventions and follow-up. In addition, the following clinical data were also extracted if available: the Cobb angle from pre-operation and post-operation to calculate the change of Cobb angle, absolute FVC and FEV1 from pre-operation and post-operation to calculate the change of absolute FVC and FEV1, and incidence of complications. Two researchers extracted the data independently according to the pre-specified inclusion and exclusion criteria. Disagreements were resolved by discussion.

The Newcastle-Ottawa Scale was used to assess the quality of case-controlled trials in terms of selection and comparability of the study groups, and determination of outcomes, with a maximum of nine points using the criteria listed in Table S1 in the Supplement [20].

\section{Data synthesis and statistical analysis}

Pairwise meta-analysis was performed with a random effects model using ADDIS software (version 1.16.6, drugis.org). In each study, the odds ratio (OR) was calculated for dichotomous outcomes, and mean differences (MDs) was calculated for continuous outcomes. Both were presented with 95\% confidence interval (CI). The pooled estimates of ORs or standardized MDs and 95\% CI of four outcomes (change of Cobb angle, change of absolute FVC, change of absolute FEV1 and incidence of complications) were determined. Heterogeneity in each result was assessed by chi-squared and $\mathrm{I}^{2}$ statistic.

Bayesian meta-analysis combined direct and indirect evidences within a Bayesian framework. The Bayesian framework was performed by ADDIS statistical software (version 1.16.6). Convergence was assessed using the Brooks-Gelman-Rubin method. This method compares within-chain and betweenchain variance to calculate the potential scale reduction factor (PSRF) for which a value close to "1" indicates approximate convergence has been reached [21]. Inconsistency was detected using the calculation of inconsistency factors and node-splitting analysis, for which an inconsistency factor close to ' 0 ' and the $95 \% \mathrm{CI}$ covers 0 mean that there is no evidence of inconsistency [22]. Node-splitting analysis allows comparing the estimated quantiles for the direct and indirect evidences as well as the combined evidences [23]. In addition, a $p$ value was shown and inconsistency would be considered statistically significant when $p$ value was less than 0.05 . A consistency model was employed for analysis with no evidence of significant inconsistency, otherwise, an inconsistency model was employed in the analysis with evidence of significant inconsistency. Bayesian approach within consistency model would allow ranking the six surgical interventions for treating AIS. The rank probability analysis was adopted to compare interventions, with Rank 1 to Rank 6 representing decreasing positive expectations from the interventions, and all interventions sharing a total possibility of 1 within each rank. For example, an intervention would be certain to be better when it obtained a higher proportion of "Rank 1", on the contrary, an intervention would be certain to be worse when it obtained a higher proportion of "Rank 6". Sensitivity analyses that switched the statistical model (consistency and inconsistency model) for each result to calculate the variance parameters were performed to determine whether results were reliable.

\section{Results}

\section{Study selection}

Figure 1 shows the study selection process. The search strategy retrieved 639 studies in total. The titles and abstracts of these studies were examined by two reviewers, and 30 studies were identified for further analysis. Two studies were excluded, as one [24] included surgical interventions other than those listed above and the other [25] did not report the outcomes that are set as criteria for our analysis. Twenty-eight case-controlled trials [15, 26-52] were considered as relevant studies and were subjected to Bayesian meta-analysis. 


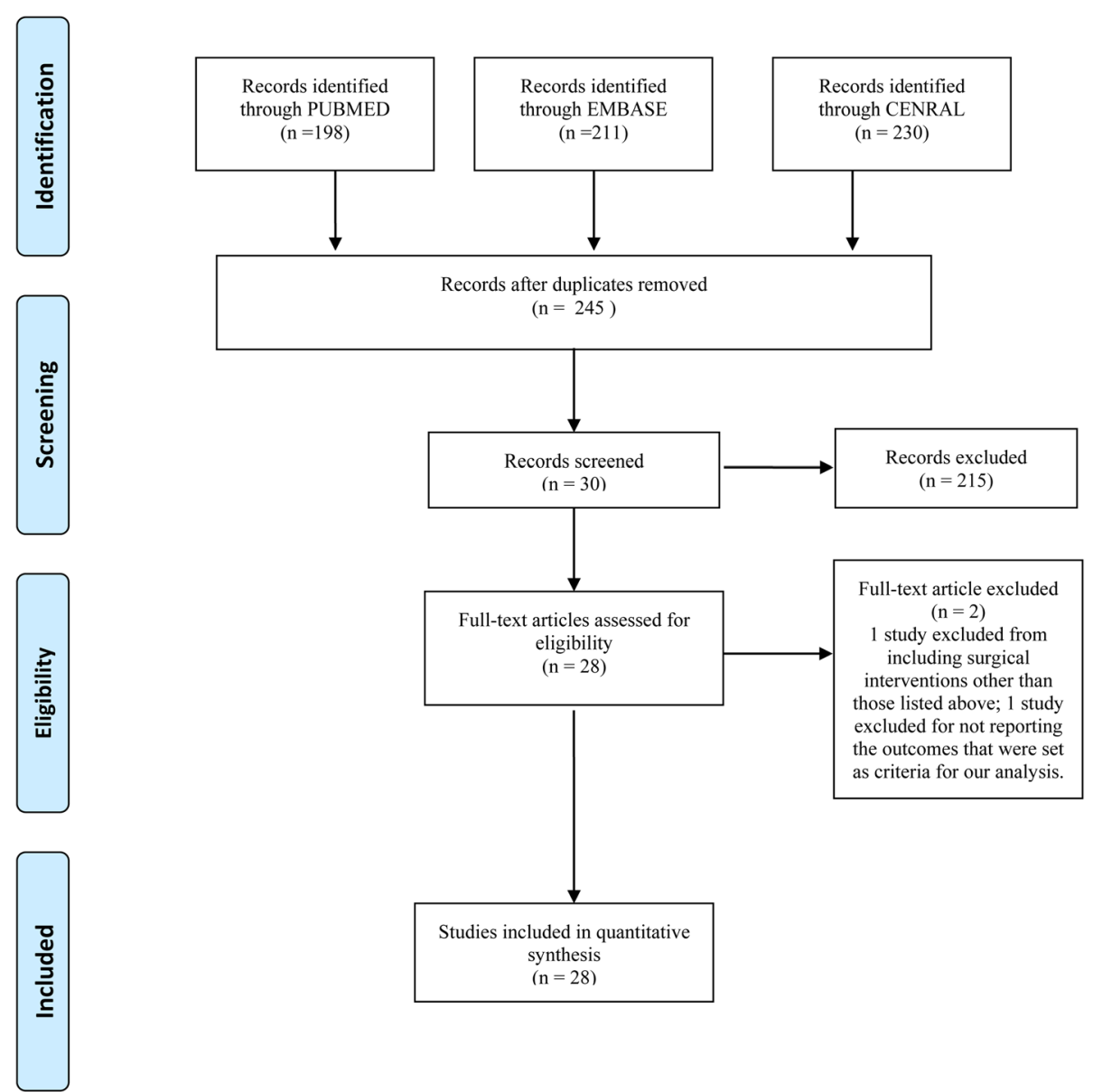

Fig. 1 Flow chart Showing Selection of Studies

\section{Characteristics and risk of bias of included trials}

Table 1 provides a summary of all the 28 studies, with totally 1970 participants included. Among all the participants, 134 patients were assigned to ASR + PSF, 873 to PSF, 399 to ASF, 211 to VAT, 292 to WT and 61 to VAT+PSF. Twenty studies reported change of Cobb angle as an outcome, 11 studies used change of absolute FVC as an outcome, 12 studies reported change of absolute FEV1 as an outcome and 14 studies reported incidence of complications as an outcome.

As assessed by the Newcastle-Ottawa Scale, one casecontrolled study [48] was awarded a score of eight points, 18 studies received a score of seven points [15, 26-29, 31-33, 35, 37, 38, 41, 42, 45, 47, 50-52], and nine studies [30, 34, 36, 39, 40, 43, 44, 46, 49] got a score of six points (Table 2).

\section{Change of absolute FVC}

Eleven trials were included in this Bayesian metaanalysis. The network of comparisons on change of absolute FVC is shown in Fig. 2a. Table 3 provides the effect sizes on change of absolute FVC from Bayesian meta-analysis and pairwise meta-analysis. Ranking plot of cumulative probability for the change of absolute FVC is shown in Fig. 2a. The Bayesian meta-analysis combining direct and indirect evidences indicated that PSF obtained a greater change of absolute FVC than ASF, VAT or WT. Meanwhile, pairwise meta-analysis also demonstrated the same comparison results between PSF and FVC, ASF, VAT or WT. Moreover, pairwise meta-analysis with limited number of trials indicated three findings that are statistically significant: Change in FVC for PSF $>$ Change in FVC for ASR + PSF; change in FVC for VAT+PSF > Change in FVC for VAT; Change in FVC for VAT > Change in FVC for WT. Based on rank probability from Bayesian meta-analysis, for obtaining a better absolute FVC outcome, PSF ranked first (0.84), followed by VAT+PSF (0.13), ASR + PSF (0.03), VAT (0.01), with ASF (0.00) and WT (0.00) being the last. Therefore, PSF had the highest possibility to obtain a higher change of absolute FVC compared with other interventions. 


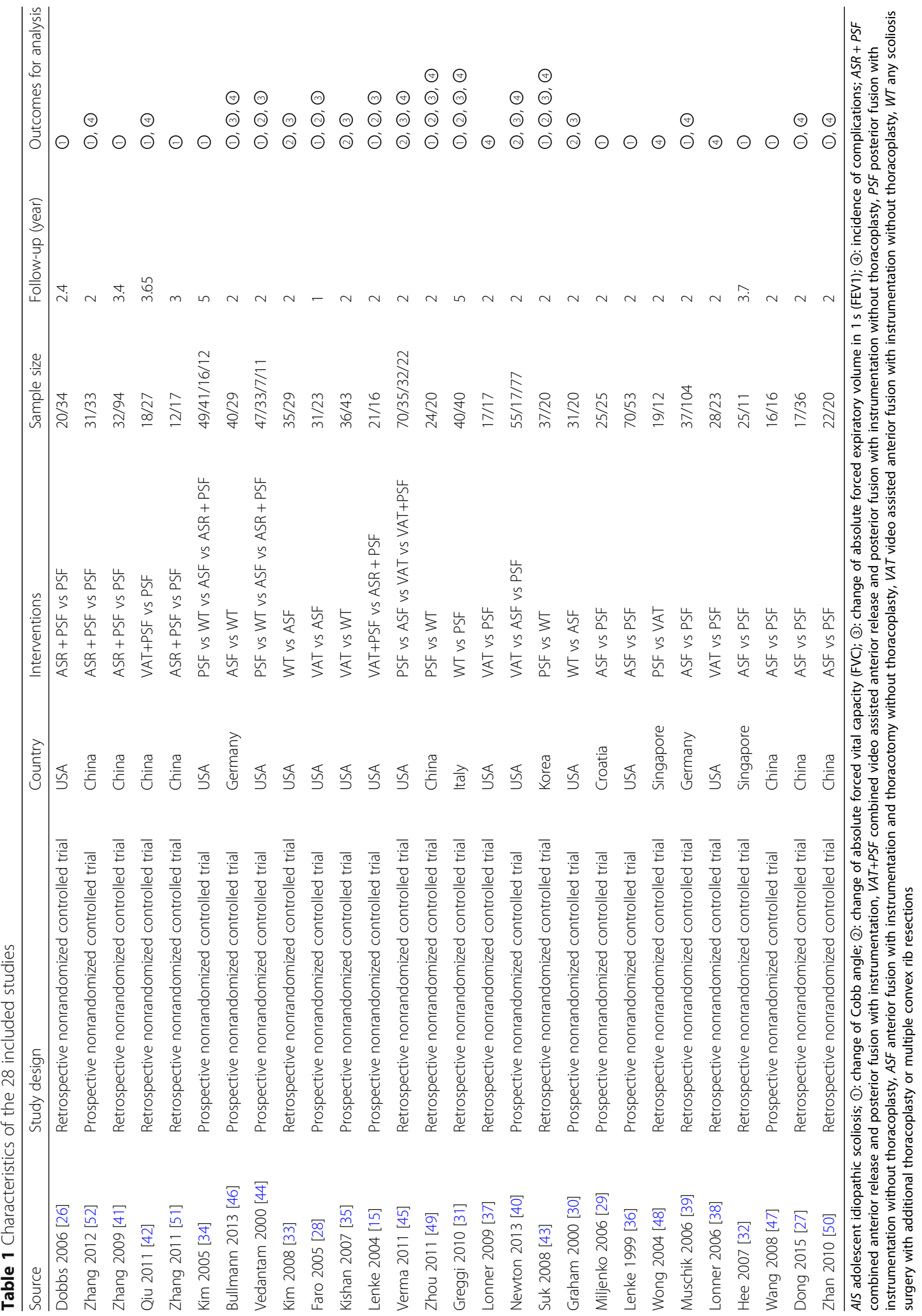




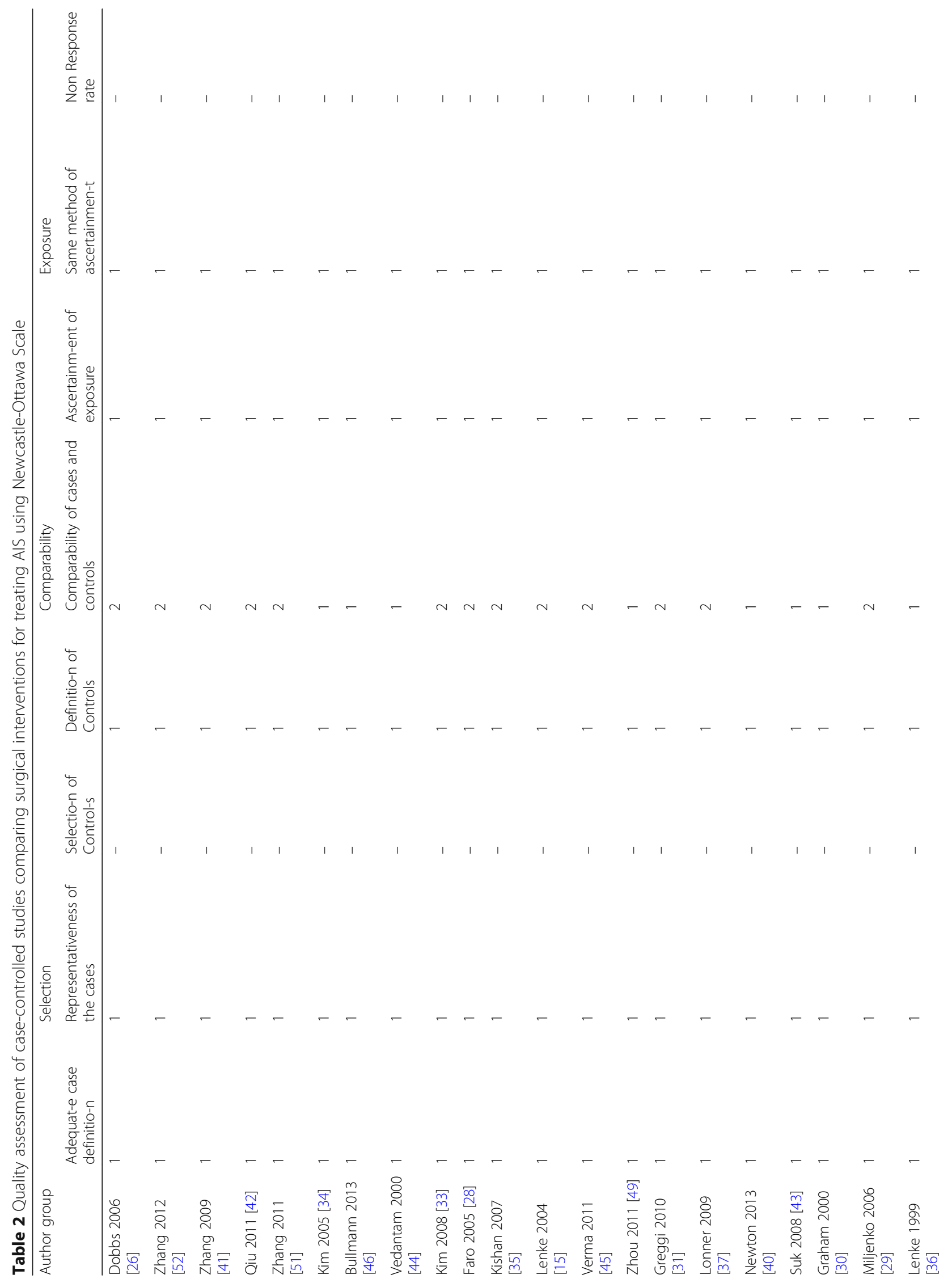




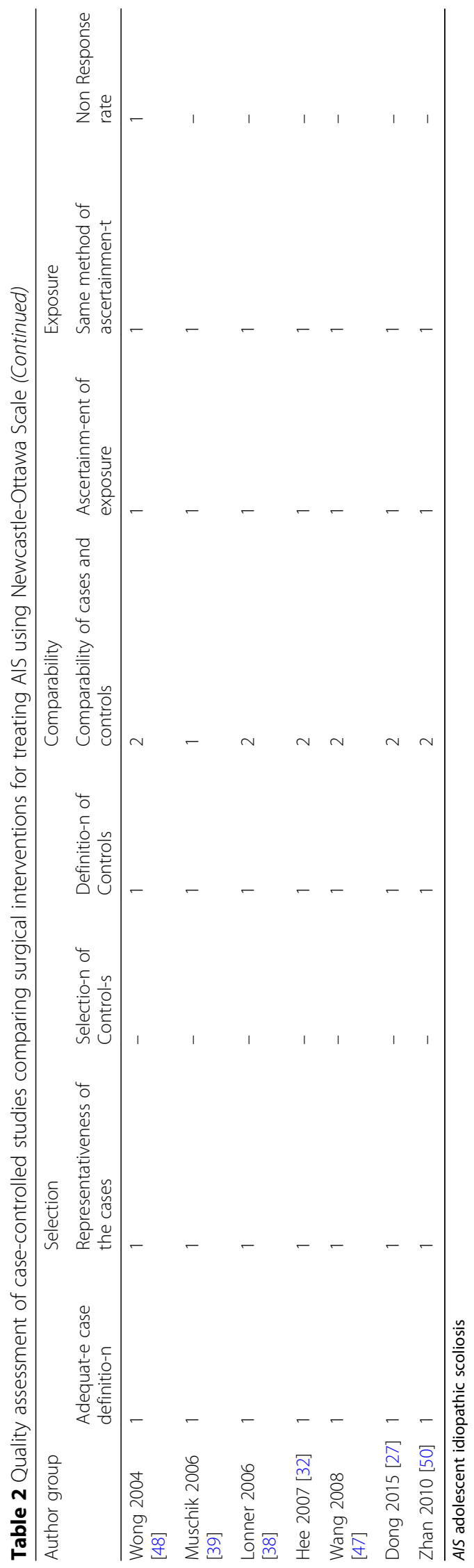




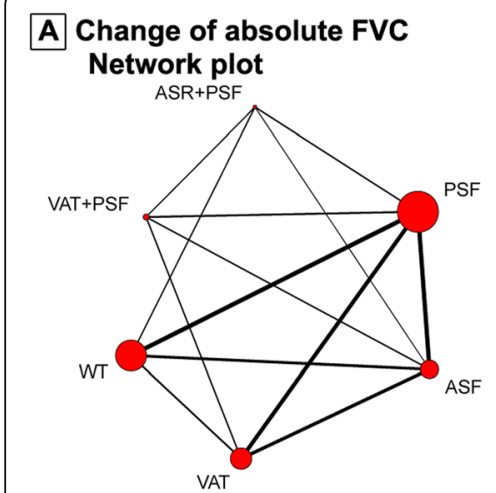

\section{Rank probability plot}

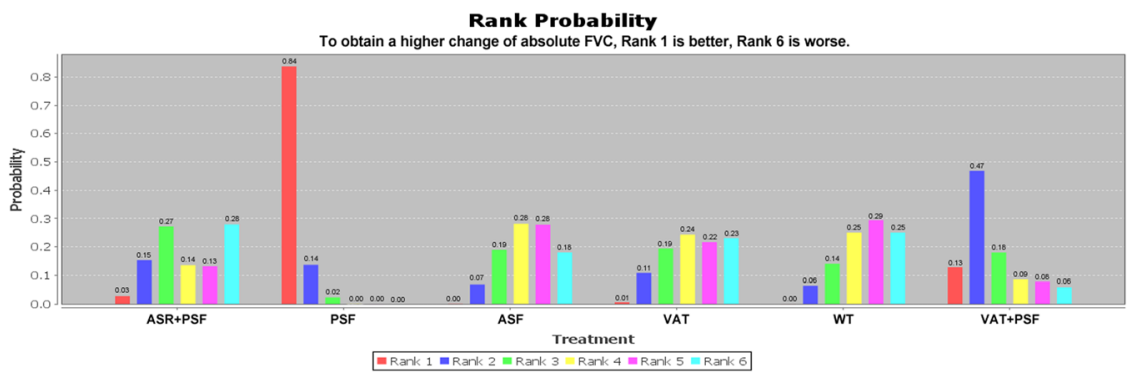

B Change of absolute FEV1 Network plot

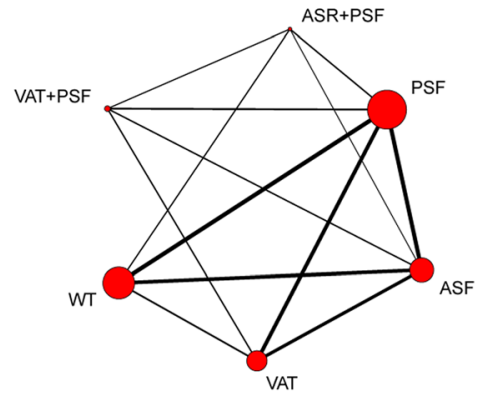

Rank probability plot

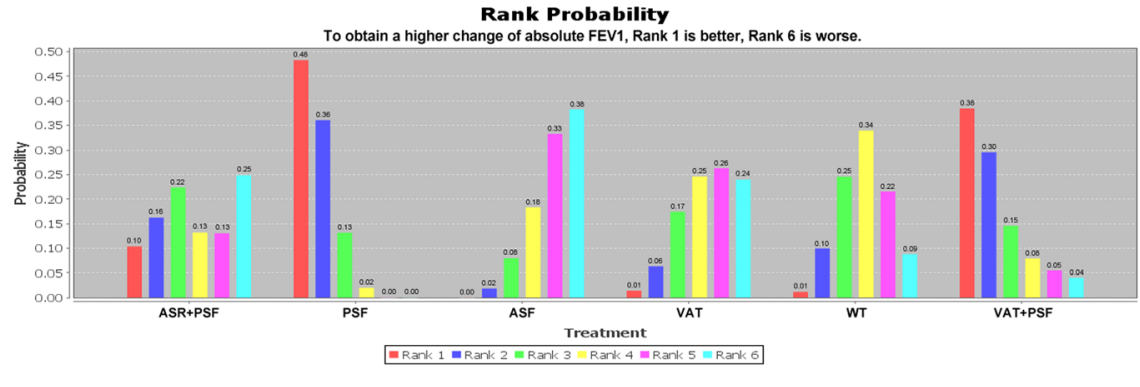

Fig. 2 Network and rank probability plots for change of absolute FVC and FEV1. For the network plots: the size of the node corresponds to the total sample size of treatments, directly comparable treatments are linked with a line, and the thickness of which represents the number of trials that were compared. FVC: forced vital capacity; FEV1: forced expiratory volume in $1 \mathrm{~s}$; ASR + PSF: combined anterior release and posterior fusion with instrumentation; VAT+PSF: combined video assisted anterior release and posterior fusion with instrumentation without thoracoplasty; PSF: posterior fusion with instrumentation without thoracoplasty; ASF: anterior fusion with instrumentation and thoracotomy without thoracoplasty; VAT: video assisted anterior fusion with instrumentation without thoracoplasty; WT: any scoliosis surgery with additional thoracoplasty or multiple convex rib resections

\section{Change of absolute FEV1}

Twelve trials were included in this Bayesian metaanalysis. The network of comparisons on change of absolute FEV1 is shown in Fig. 2. Table 3 provides the effect sizes on change of absolute FEV1 from Bayesian meta-analysis and pairwise meta-analysis. Ranking plot of cumulative probability for change of absolute FEV1 are presented in Fig. 2b. Both Bayesian meta-analysis and pairwise meta-analysis demonstrated that PSF had a higher change of absolute FEV1 than ASF. In addition, pairwise metaanalysis with limited number of trials claimed the following: Change in FEV1 of PSF > Change in FEV1 of ASR + PSF or WT; Change in FEV1 for $\mathrm{VAT}+\mathrm{PSF}>\mathrm{Change}$ in FEV1 for VAT; and Change in FEV1 for VAT > Change in FEV1 for WT. Based on rank probability, for obtaining a higher change of absolute FEV1, the ranking of all surgical interventions was: PSF (0.48), VAT+PSF (0.38), ASR + PSF (0.10), VAT (0.01), WT (0.01) and ASF (0.00). PSF turned out to have the highest possibility to obtain a higher change of absolute FEV1 compared with other interventions.

\section{Incidence of complications}

Fourteen trials were included in this Bayesian metaanalysis. The network of comparisons on incidence of complications was shown in Fig. 3a. Table 3 provides the effect sizes on incidence of complications from Bayesian meta-analysis and pairwise meta-analysis. Ranking plot of cumulative probability for incidence of complications is displayed in Fig. 3a. Pairwise metaanalysis with limited number of trials indicated that ASR + PSF resulted in higher incidence of complications than PSF, and there was a higher rate of complications for VAT+PSF compared to ASF. However, Bayesian meta-analysis with 14 trials demonstrated that there was no significant difference among ASR + PSF, VAT+PSF, PSF, ASF, VAT and WT for the incidence of complications. Based on rank probability, for resulting in higher incidence of complications, the ranking of surgical interventions was: ASR + PSF (0.73), VAT+PSF (0.21), VAT (0.03), WT (0.01), ASF (0.01) and PSF (0.00); for obtaining lower incidence of complications, the ranking of surgical interventions was: PSF (0.42), WT (0.39), ASF (0.08), VAT (0.05), VAT+PSF (0.03) and ASR + PSF (0.02). Therefore, ASR + PSF had the highest possibility 
Table 3 Statistical analysis results from Bayesian meta-analysis (gray background) and pairwise meta-analysis (white background)

\begin{tabular}{|c|c|c|c|c|c|c|}
\hline \multirow{6}{*}{$\begin{array}{c}\text { Change of } \\
\text { absolute FVC }\end{array}$} & ASR+PSF & $-0.81(-1.27,-0.35)$ & $0.15(-0.42,0.72)$ & NA & $-0.13(-0.62,0.36)$ & $0.01(-0.44,0.46)$ \\
\hline & $-0.49(-1.06,0.07)$ & PSF & $0.56(0.24,0.88)$ & $0.84(0.57,1.11)$ & $0.48(0.29,0.67)$ & $0.19(-0.23,0.61)$ \\
\hline & $0.04(-0.54,0.62)$ & $0.53(0.21,0.87)$ & ASF & $0.15(-0.53,0.84)$ & $-0.01(-0.22,0.20)$ & $-0.15(-0.58,0.28)$ \\
\hline & $0.04(-0.60,0.67)$ & $0.53(0.10,0.95)$ & $-0.00(-0.40,0.38)$ & VAT & $0.40(0.18,0.62)$ & $-0.65(-1.07,-0.23)$ \\
\hline & $0.06(-0.52,0.64)$ & $0.55(0.25,0.85)$ & $0.02(-0.31,0.33)$ & $0.03(-0.40,0.42)$ & WT & $\mathrm{NA}$ \\
\hline & $-0.19(-0.77,0.37)$ & $0.29(-0.26,0.85)$ & $-0.24(-0.79,0.31)$ & $-0.23(-0.83,0.36)$ & $-0.26(-0.82,0.33)$ & VAT + PSF \\
\hline \multirow{6}{*}{$\begin{array}{c}\text { Change of } \\
\text { absolute } \\
\text { FEV1 }\end{array}$} & $\mathbf{A S R}+\mathbf{P S F}$ & $-0.55(-0.94,-0.16)$ & $-0.04(-0.56,0.46)$ & NA & $-0.08(-0.48,0.32)$ & $0.12(-0.39,0.63)$ \\
\hline & $-0.25(-0.81,0.29)$ & PSF & $0.31(0.15,0.46)$ & $0.35(-0.34,1.03)$ & $0.29(0.10,0.47)$ & $0.00(-0.29,0.29)$ \\
\hline & $0.12(-0.45,0.69)$ & $0.37(0.06,0.69)$ & ASF & $0.08(-0.28,0.44)$ & $-0.20(-0.48,0.09)$ & $-0.31(-0.60,-0.02)$ \\
\hline & $0.07(-0.52,0.66)$ & $0.32(-0.04,0.68)$ & $-0.05(-0.39,0.28)$ & VAT & $0.30(0.14,0.46)$ & $-0.70(-0.98,-0.42)$ \\
\hline & $0.02(-0.55,0.58)$ & $0.27(-0.02,0.55)$ & $-0.10(-0.39,0.18)$ & $-0.05(-0.41,0.32)$ & WT & NA \\
\hline & $-0.21(-0.79,0.39)$ & $0.04(-0.48,0.57)$ & $-0.33(-0.86,0.20)$ & $-0.28(-0.82,0.27)$ & $-0.22(-0.77,0.34)$ & VAT+PSF \\
\hline \multirow{6}{*}{$\begin{array}{l}\text { Incidence of } \\
\text { complications }\end{array}$} & $\mathbf{A S R}+\mathbf{P S F}$ & $12.76(2.59,62.93)$ & NA & NA & NA & NA \\
\hline & $18.38(0.78,474.57)$ & PSF & $0.52(0.21,1.33)$ & $0.44(0.17,1.14)$ & $1.97(0.40,9.75)$ & $0.28(0.02,4.53)$ \\
\hline & $11.05(0.37,356.06)$ & $0.56(0.16,2.13)$ & ASF & $0.79(0.09,7.07)$ & $2.17(0.52,9.00)$ & $0.08(0.01,0.71)$ \\
\hline & $8.43(0.26,274.06)$ & $0.42(0.11,1.77)$ & $0.76(0.14,3.83)$ & VAT & NA & $0.38(0.09,1.55)$ \\
\hline & $17.93(0.44,544.81)$ & $0.89(0.16,4.60)$ & $1.51(0.21,9.45)$ & $2.00(0.23,16.64)$ & WT & NA \\
\hline & $3.64(0.08,163.10)$ & $0.17(0.02,1.80)$ & $0.29(0.03,3.53)$ & $0.39(0.04,4.61)$ & $0.22(0.02,3.45)$ & VAT + PSF \\
\hline \multirow{6}{*}{$\begin{array}{l}\text { Change of } \\
\text { Cobb angle }\end{array}$} & ASR+PSF & $-2.39(-8.96,4.17)$ & $-2.19(-10.43,6.05)$ & NA & $3.47(-3.15,10.10)$ & $-3.88(-15.23,7.47)$ \\
\hline & $-2.32(-7.86,3.33)$ & PSF & $-2.83(-7.20,1.55)$ & NA & $-2.15(-4.44,0.14)$ & $-2.00(-6.33,2.33)$ \\
\hline & $-4.87(-11.58,2.00)$ & $-2.54(-7.09,1.99)$ & ASF & $-1.55(-6.21,3.11)$ & $2.21(-2.30,6.72)$ & NA \\
\hline & $-6.61(-21.67,8.65)$ & $-4.28(-18.59,10.39)$ & $-1.78(-15.45,12.48)$ & VAT & NA & NA \\
\hline & $-3.58(-10.99,4.03)$ & $-1.30(-6.90,4.47)$ & $1.24(-5.12,7.74)$ & $3.06(-12.17,17.74)$ & WT & NA \\
\hline & $-4.06(-15.44,7.20)$ & $-1.74(-12.91,9.06)$ & $0.83(-10.99,12.17)$ & $2.57(-15.75,20.52)$ & $-0.44(-12.74,11.62)$ & VAT + PSF \\
\hline
\end{tabular}

AIS adolescent idiopathic scoliosis, FVC forced vital capacity, FEV1 forced expiratory volume in $1 \mathrm{~s}, A S R+P S F$ combined anterior release and posterior fusion with instrumentation, VAT+PSF combined video assisted anterior release and posterior fusion with instrumentation without thoracoplasty, PSF posterior fusion with instrumentation without thoracoplasty, ASF anterior fusion with instrumentation and thoracotomy without thoracoplasty, VAT video assisted anterior fusion with instrumentation without thoracoplasty, $W T$ any scoliosis surgery with additional thoracoplasty or multiple convex rib resections, NA not applicable

to obtain higher incidence of complications compared with other interventions; meanwhile, PSF had the highest possibility to obtain lower incidence of complications compared with other interventions.

\section{Change of cobb angle}

Twenty trials were included in this Bayesian metaanalysis. The network of comparisons on change of Cobb angle is shown in Fig. $3 \mathrm{~b}$. Table 3 provides the effect sizes on change of Cobb angle from Bayesian meta-analysis and pairwise meta-analysis. Ranking plot presenting the cumulative probability for change of Cobb angle is displayed in Fig. 3b. Both Bayesian meta-analysis and pairwise meta-analysis indicated no statistically significant difference among ASR + PSF, VAT+PSF, PSF, ASF, VAT and WT approaches for the change of Cobb angle. Based on rank probability, to get a higher change of Cobb angle, the ranking of surgical interventions was: VAT (0.47), VAT+PSF (0.25), ASF (0.15), WT (0.10), ASR + PSF (0.01) and
PSF (0.01). So VAT had the highest possibility to obtain greater change of Cobb angle compared with other interventions.

\section{Inconsistency and sensitivity analysis}

In general, the results obtained from the pairwise meta-analysis closely matched those from the Bayesian meta-analysis. Table 4 presents the results of inconsistency factors for each outcome. All of the inconsistency factors were close to ' 0 ' and the $95 \%$ CI covered ' 0 ', which indicated that no inconsistency was identified in the Bayesian analysis. Moreover, Node-splitting analysis also demonstrated that there was no inconsistency in Bayesian meta-analysis except for the comparison between PSF and VAT in change of absolute FVC (Table 5). The sensitivity analysis was performed by comparing the random effects standard deviation of different models (consistency and inconsistency model). The random effects standard deviation of consistency model was 


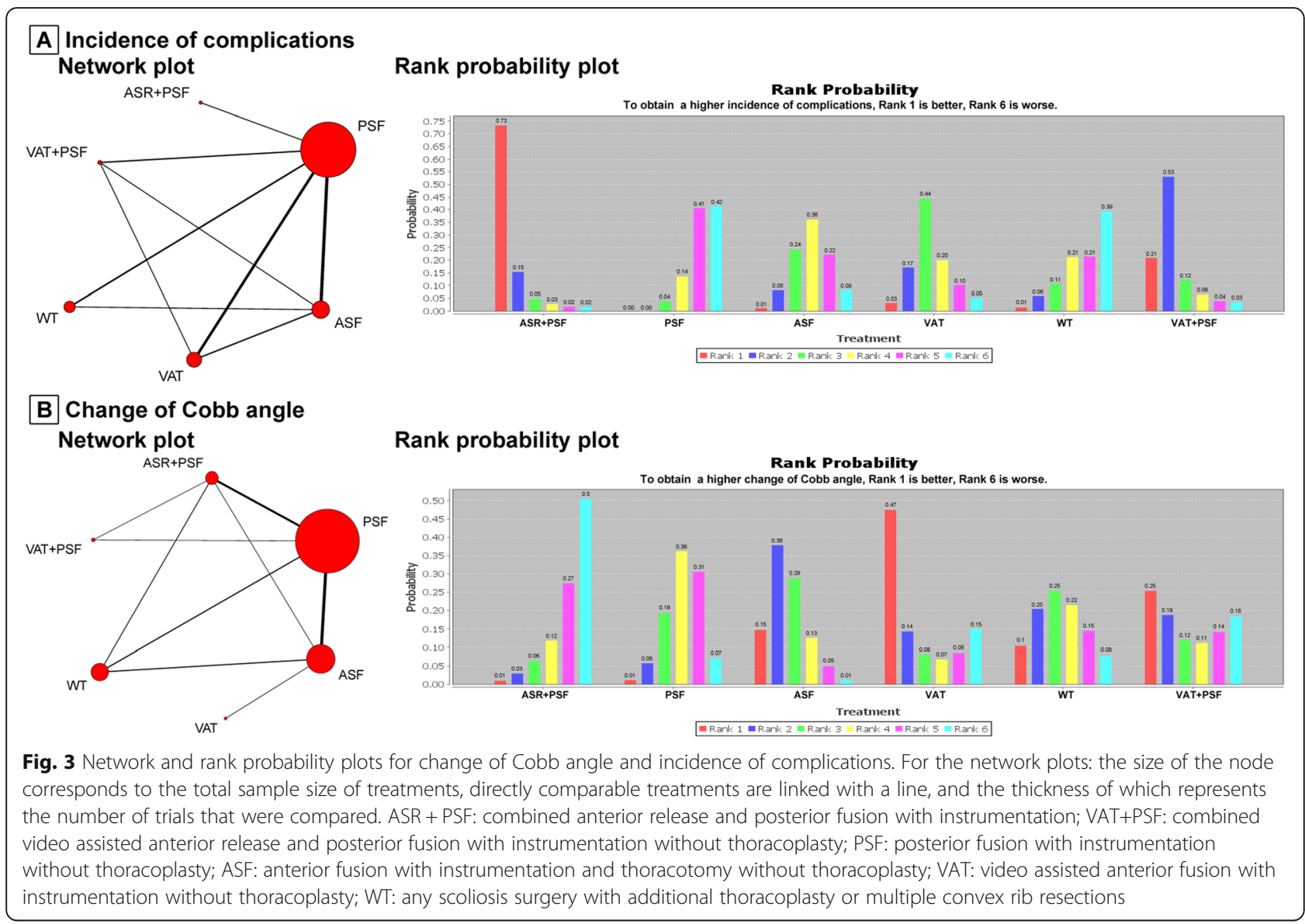

similar to the inconsistency model, demonstrating statistically robust results for both outcomes (Table 6).

\section{Discussion}

This Bayesian meta-analysis pooled the data from 28 case-controlled trials, with 1970 participants distributed in ASR + PSF, VAT+PSF, PSF, ASF, VAT or WT groups. To best of our knowledge, this is the first Bayesian meta-analysis combining direct and indirect evidences to provide comprehensive comparisons among multiple surgical interventions for treating AIS that takes 4 criteria into consideration: change of Cobb angle, absolute FVC and absolute FEV1 from pre-operation to postoperation, and incidence of complications. In this analysis, we found that PSF had the highest possibility to obtain a greater change of absolute FVC and FEV1 and a lower incidence of complications compared with other interventions based on rank probability. Moreover, VAT had the highest possibility to obtain greater change of Cobb angle.

Based on the quality assessment evaluated by Newcastle-Ottawa Scale, 9 studies were scored 6 with all others scored at least 7 , suggesting that the included studies have moderate or high quality. In the node-splitting analysis, the only inconsistency was found between PSF and VAT when comparing change of absolute FVC. We checked the inclusion and statistical processes to find the reason for the inconsistency and noticed that only one study reported this comparison. However, the results of inconsistency factors demonstrated that there was no inconsistency in this Bayesian meta-analysis. In general, the results from this Bayesian meta-analysis were reliable and robust.

Spinal deformity can profoundly affect pulmonary function by alternation of lung development, which may cause early mortality through respiratory failure [53]. So early interventions are recommended to prevent and correct the development of the spinal deformity. FVC and FEV1 were considered as two common parameters to assess the patients' pulmonary functions preoperatively and post-operatively. Several traditional meta-analyses comparing only two surgical interventions for FVC and FEV1 have been published. Chen et al. [2] reported that posterior surgery could achieve similar improvement in percent-predicted FVC compared to combined anterior-posterior surgery. Lee et al. [16] found 
Table 4 Inconsistency Factors for each outcome

\begin{tabular}{|c|c|c|}
\hline Outcome & Cycle & Median $(95 \% \mathrm{Crl})$ \\
\hline \multirow[t]{4}{*}{ Change of Cobb angle } & ASR + PSF; PSF; ASF & $-0.44(-9.14,5.87)$ \\
\hline & ASR + PSF; PSF; ASF; WT & $0.73(-6.35,11.07)$ \\
\hline & ASR + PSF; PSF; VAT+PSF & $-0.02(-9.81,10.07)$ \\
\hline & PSF; ASF; WT & $-0.45(-10.09,6.72)$ \\
\hline \multirow[t]{4}{*}{ Incidence of complications } & PSF; ASF; VAT & $0.07(-1.54,1.92)$ \\
\hline & PSF; ASF; VAT; VAT+PSF & $-0.06(-2.08,1.63)$ \\
\hline & PSF; ASF; WT & $-0.04(-2.18,1.66)$ \\
\hline & PSF; ASF; VAT+PSF & $0.17(-1.17,2.62)$ \\
\hline \multirow[t]{8}{*}{ Change of absolute FEV1 } & ASR + PSF; PSF; ASF; VAT; VAT+PSF & $-0.01(-0.45,0.51)$ \\
\hline & ASR + PSF; PSF; VAT; VAT+PSF & $0.15(-0.13,0.86)$ \\
\hline & ASR + PSF; PSF; VAT+PSF & $-0.01(-0.44,0.43)$ \\
\hline & PSF; ASF; VAT & $-0.00(-0.53,0.47)$ \\
\hline & PSF; ASF; VAT & $-0.00(-0.53,0.47)$ \\
\hline & PSF; ASF; VAT; WT & $0.01(-0.42,0.55)$ \\
\hline & PSF; ASF; VAT; WT & $0.01(-0.42,0.55)$ \\
\hline & ASF; VAT; WT & $-0.09(-0.68,0.20)$ \\
\hline \multirow[t]{7}{*}{ Change of absolute FVC } & ASR + PSF; PSF; VAT+PSF & $0.05(-0.36,0.77)$ \\
\hline & PSF; ASF; VAT; WT & $-0.00(-0.52,0.71)$ \\
\hline & PSF; ASF; VAT; WT & $-0.00(-0.52,0.71)$ \\
\hline & PSF; VAT; WT & $-0.06(-0.76,0.41)$ \\
\hline & PSF; VAT; WT & $-0.06(-0.76,0.41)$ \\
\hline & ASF; VAT; WT & $-0.04(-0.76,0.42)$ \\
\hline & ASF; VAT; WT & $-0.04(-0.76,0.42)$ \\
\hline
\end{tabular}

$A S R+P S F$ combined anterior release and posterior fusion with instrumentation, VAT+PSF combined video assisted anterior release and posterior fusion with instrumentation without thoracoplasty, PSF posterior fusion with instrumentation without thoracoplasty, ASF anterior fusion with instrumentation and

thoracotomy without thoracoplasty, VAT video assisted anterior fusion with instrumentation without thoracoplasty, $W-T$ any scoliosis surgery with additional thoracoplasty or multiple convex rib resections, FEV1 forced expiratory volume in $1 \mathrm{~s}$, FVC forced vital capacity

that posterior spinal fusion with instrumentations resulted in small to moderate increases in FVC and FEV1. It seems that posterior surgery gave better pulmonary function than anterior or combined anterior-posterior surgeries. As shown in this present Bayesian metaanalysis, PSF obtained a greater change of absolute FVC than ASF, VAT or WT, and also had a greater change of absolute FEV1 than ASF, which is in agreement of the previous reports. Moreover, based on rank probability, PSF had the highest possibility to obtain greater change of absolute FVC and FEV1 compared with other five surgical interventions. The results also reproduced a reported trend that the amount of PSF surgery is increasing year by year, while the amount of thoracoplasty is decreasing gradually [54].

Incidence of complications is important to evaluate the safety of different surgical interventions. Chen et al. [2] previously reported that posterior-only surgery achieved lower complication rate compared to combined anteriorposterior surgery. Lonner et al. [54] performed a retrospective review of the prospective AIS registry and demonstrated that as the amount of PSF surgery increases, the incidence of complications gradually decreases from 1995 to 2013. Those studies comparing limited kinds of surgical interventions indicated that posterior surgery might achieve lower complication rate. However, our Bayesian meta-analysis including 14 trials revealed that there was no statistically significant difference among $\mathrm{ASR}+\mathrm{PSF}, \mathrm{VAT}+\mathrm{PSF}, \mathrm{PSF}, \mathrm{ASF}, \mathrm{VAT}$ and WT in incidence of complications. But we still found that PSF had the highest possibility to obtain lower incidence of complications compared with other five surgical interventions based on rank probability, which agreed to the previous studies. This may be attributed to the low implant-related complications of posterior pedicle-screw and enhanced surgeon experiences [54, 55].

Cobb angle measurement is a traditional method to assess the spine deformity of AIS, which is carried out in the coronal plane using a standard postero-anterior radiograph [5]. Previous studies focused on discussing the coronal plane correction between anterior and posterior surgery. Luo et al. [56] reported that the posterior 
Table 5 Node-splitting analysis for inconsistency of Bayesian meta-analysis

\begin{tabular}{|c|c|c|c|c|c|}
\hline Outcome & Comparison & Direct Effect & Indirect Effect & Bayesian Effect & $\boldsymbol{P}$-Value \\
\hline \multirow[t]{8}{*}{ Change of Cobb angle } & ASR + PSF vS PSF & $2.51(-3.61,8.50)$ & $-0.72(-11.35,9.36)$ & $2.32(-3.33,7.86)$ & 0.54 \\
\hline & $A S R+P S F$ vS ASF & $5.00(-8.04,16.68)$ & $3.99(-3.65,11.34)$ & $4.87(-2.00,11.58)$ & 0.87 \\
\hline & $A S R+P S F$ vs WT & $-1.35(-12.88,9.45)$ & $5.95(-3.23,14.94)$ & $3.58(-4.03,10.99)$ & 0.27 \\
\hline & $A S R+P S F$ vs VAT+PSF & $4.19(-13.65,22.04)$ & $4.34(-11.59,19.54)$ & $4.06(-7.20,15.44)$ & 1 \\
\hline & PSF vs ASF & $2.79(-1.98,7.84)$ & $0.68(-15.13,16.43)$ & $2.54(-1.99,7.09)$ & 0.79 \\
\hline & PSF vs WT & $2.36(-3.81,8.75)$ & $2.88(-12.15,17.75)$ & $1.30(-4.47,6.90)$ & 0.94 \\
\hline & PSF vs VAT+PSF & $2.02(-11.94,16.18)$ & $1.52(-16.87,20.19)$ & $1.74(-9.06,12.91)$ & 0.96 \\
\hline & ASF vs WT & $-2.88(-11.90,5.60)$ & $1.27(-8.31,10.93)$ & $-1.24(-7.74,5.12)$ & 0.49 \\
\hline \multirow[t]{6}{*}{ Incidence of Complications } & PSF vs ASF & $0.57(-1.03,2.07)$ & $1.14(-2.80,5.17)$ & $0.53(-0.78,1.76)$ & 0.77 \\
\hline & PSF vs WT & $0.26(-1.73,2.48)$ & $-0.38(-3.99,3.08)$ & $0.05(-1.57,1.84)$ & 0.72 \\
\hline & ASF vs VAT & $0.32(-2.02,2.69)$ & $-0.17(-2.58,2.62)$ & $0.26(-1.32,1.96)$ & 0.75 \\
\hline & ASF vs WT & $-0.85(-4.21,2.55)$ & $-0.19(-2.63,2.59)$ & $-0.48(-2.26,1.54)$ & 0.73 \\
\hline & ASF vs VAT+PSF & $2.17(-0.74,5.60)$ & $-1.16(-5.64,2.77)$ & $1.08(-1.28,3.41)$ & 0.15 \\
\hline & VAT vs VAT+PSF & $1.30(-1.85,4.17)$ & $-1.39(-5.94,2.57)$ & $0.84(-1.59,3.08)$ & 0.26 \\
\hline \multirow[t]{13}{*}{ Change of absolute FEV1 } & $A S R+P S F$ vS PSF & $0.49(-0.23,1.25)$ & $0.14(-0.48,0.75)$ & $0.25(-0.29,0.81)$ & 0.4 \\
\hline & $A S R+P S F$ vS ASF & $-0.04(-0.83,0.82)$ & $-0.14(-0.75,0.50)$ & $-0.12(-0.69,0.45)$ & 0.84 \\
\hline & $A S R+P S F$ vs WT & $0.01(-0.75,0.76)$ & $0.02(-0.60,0.62)$ & $-0.02(-0.58,0.55)$ & 0.98 \\
\hline & $A S R+P S F$ vs VAT+PSF & $-0.13(-0.91,0.66)$ & $0.56(-0.28,1.40)$ & $0.21(-0.39,0.79)$ & 0.23 \\
\hline & PSF vs ASF & $-0.32(-0.72,0.07)$ & $-0.48(-0.91,-0.03)$ & $-0.37(-0.69,-0.06)$ & 0.56 \\
\hline & PSF vs VAT & $-0.35(-0.79,0.09)$ & $-0.14(-0.67,0.38)$ & $-0.32(-0.68,0.04)$ & 0.51 \\
\hline & PSF vs WT & $-0.28(-0.64,0.07)$ & $-0.28(-0.79,0.23)$ & $-0.27(-0.55,0.02)$ & 0.97 \\
\hline & PSF vs VAT+PSF & $0.01(-0.68,0.70)$ & $-0.56(-1.56,0.47)$ & $-0.04(-0.57,0.48)$ & 0.34 \\
\hline & ASF vs VAT & $-0.07(-0.41,0.27)$ & $0.46(-0.15,1.08)$ & $0.05(-0.28,0.39)$ & 0.11 \\
\hline & ASF vs WT & $0.18(-0.16,0.53)$ & $-0.04(-0.53,0.44)$ & $0.10(-0.18,0.39)$ & 0.4 \\
\hline & ASF vs VAT+PSF & $0.34(-0.35,1.01)$ & $-0.20(-1.21,0.81)$ & $0.33(-0.20,0.86)$ & 0.35 \\
\hline & VAT vs WT & $-0.30(-0.89,0.31)$ & $0.20(-0.20,0.61)$ & $0.05(-0.32,0.41)$ & 0.16 \\
\hline & VAT vs VAT+PSF & $0.65(0.00,1.33)$ & $-0.25(-1.28,0.80)$ & $0.28(-0.27,0.82)$ & 0.15 \\
\hline \multirow[t]{13}{*}{ Change of absolute FVC } & $A S R+P S F$ vS PSF & $0.75(0.00,1.50)$ & $0.35(-0.26,0.98)$ & $0.49(-0.07,1.06)$ & 0.31 \\
\hline & $A S R+P S F$ vS ASF & $-0.25(-1.03,0.57)$ & $0.07(-0.55,0.68)$ & $-0.04(-0.62,0.54)$ & 0.44 \\
\hline & $A S R+P S F$ vs WT & $0.05(-0.72,0.91)$ & $-0.09(-0.78,0.60)$ & $-0.06(-0.64,0.52)$ & 0.72 \\
\hline & $A S R+P S F$ vs VAT+PSF & $-0.00(-0.77,0.75)$ & $0.53(-0.43,1.44)$ & $0.19(-0.37,0.77)$ & 0.36 \\
\hline & PSF vs ASF & $-0.54(-0.98,-0.14)$ & $-0.58(-1.10,-0.06)$ & $-0.53(-0.87,-0.21)$ & 0.91 \\
\hline & PSF vs VAT & $-0.90(-1.26,-0.48)$ & $-0.17(-0.50,0.16)$ & $-0.53(-0.95,-0.10)$ & 0.02 \\
\hline & PSF vs WT & $-0.47(-0.79,-0.15)$ & $-0.86(-1.36,-0.34)$ & $-0.55(-0.85,-0.25)$ & 0.17 \\
\hline & PSF vs VAT+PSF & $-0.18(-0.90,0.56)$ & $-0.68(-1.68,0.36)$ & $-0.29(-0.85,0.26)$ & 0.4 \\
\hline & ASF vs VAT & $-0.15(-0.56,0.26)$ & $0.43(-0.19,1.08)$ & $0.00(-0.38,0.40)$ & 0.1 \\
\hline & ASF vs WT & $0.01(-0.41,0.46)$ & $-0.03(-0.53,0.49)$ & $-0.02(-0.33,0.31)$ & 0.9 \\
\hline & ASF vs VAT+PSF & $0.22(-0.56,0.95)$ & $-0.15(-1.18,0.92)$ & $0.24(-0.31,0.79)$ & 0.54 \\
\hline & VAT vs WT & $-0.40(-0.96,0.14)$ & $0.22(-0.21,0.69)$ & $-0.03(-0.42,0.40)$ & 0.07 \\
\hline & VAT Vs VAT+PSF & $0.57(-0.15,1.34)$ & $-0.16(-1.25,0.92)$ & $0.23(-0.36,0.83)$ & 0.23 \\
\hline
\end{tabular}

ASR + PSF combined anterior release and posterior fusion with instrumentation, VAT+PSF combined video assisted anterior release and posterior fusion with instrumentation without thoracoplasty, PSF posterior fusion with instrumentation without thoracoplasty, ASF anterior fusion with instrumentation and thoracotomy without thoracoplasty, VAT video assisted anterior fusion with instrumentation without thoracoplasty, $W-T$ any scoliosis surgery with additional thoracoplasty or multiple convex rib resections, FEV1 forced expiratory volume in $1 \mathrm{~s}, F V C$ forced vital capacity 
Table 6 Random Effects Standard Deviation of Different Models for Sensitivity Analysis

\begin{tabular}{llr}
\hline Outcome & Model for Random Effects Standard Deviation & Median (95\% Cl) \\
\hline Change of Cobb angle & Consistency model & $6.28(4.20,9.67)$ \\
& Inconsistency model & $6.40(4.31,9.95)$ \\
Incidence of complications & Consistency model & $1.14(0.02,2.31)$ \\
Change of absolute FEV1 & Inconsistency model & $1.26(0.38,2.39)$ \\
& Consistency model & $0.29(0.18,0.50)$ \\
Change of absolute FVC & inconsistency model & $0.26(0.11,0.49)$ \\
& Consistency model & $0.27(0.13,0.53)$ \\
\hline
\end{tabular}

FEV1 forced expiratory volume in $1 \mathrm{~s}$, FVC forced vital capacity

approach can obtain a larger change of Cobb angle from pre-operation to final follow-up. Franic et al. [17] found that both anterior and posterior surgeries provided a similar degree of reduction of frontal Cobb angle, and long-term effects of surgical correction on the sagittal Cobb angle seemed to be more stable in posterior group. However, in this study, both Bayesian meta-analysis and pairwise meta-analysis indicated no statistically significant difference among ASR + PSF, VAT+PSF, PSF, ASF, VAT and WT approaches for the change of Cobb angle. Furthermore, the rank probability of outcomes was used to distinguish the subtle differences of change in Cobb angle among the six interventions, which revealed that VAT had the highest possibility to obtain greater change of Cobb angle. In addition, VAT also resulted in less invasive, fewer levels fused and better satisfaction [57]. However, it had a long learning curve and specific indications. Therefore, with appropriate training and careful patient selection, VAT might be a more effective surgical intervention compared to traditional surgical interventions.

Refering to the classification system, Lenke classification system is the most common classification system for AIS, but it can not definitely decide the surgery strategies. Among the RCTs which we included, most of them didn't discuss the classification of AIS, they just simply defined severe AIS as the Cobb's angle for main curve $\geq 90^{\circ}$. So, we only focus on the choice of the surgery approaches for AIS in this analysis. The selection of the upper instrumented vertebra (UIV), lower instrumented vertebra (LIV) and the instrumented segment was not taken into our consideration. For the surgery approaches, we suggest that PSF still is the primary choice for AIS because of the minimal influence on pulmonary function and low complication rate. Moreover, the deformity correction rate of PSF is comparable to the other surgery approaches. However, anterior approach combined with posterior approach might be necessary to the patients with severe AIS for maximum correction of deformity. Compared to ASF approach, VAT approach was more more minimally invasive, and has advantages in deformity correction because of less damage to the tissue and less blood loss. However, ASF approach is also a choice for AIS because the VAT approach has a long learning curve for surgeons. The VAT+PSF approach could deal with the severe AIS, which is the tendency for surgery approaches nowadays. And the WT approach should be avoided as as much as possible because of the adverse effects on pulmonary function.

This Bayesian meta-analysis has several limitations. Firstly, this study only included case-controlled studies, because randomized controlled trials are challenging to perform in pediatric population [58], and the casecontrolled studies may have reduced the quality of the evidences; Secondly, because of the limited number of included studies, we did not distinguish different kind of complications, such as infection, neurologic deficit and instrumentation failure. Instead, all of the complications reported in the included studies were recorded as incidence of complications for statistical analysis; Finally, though Lenke classification is a useful scale to guide the treatment of AIS, this analysis did not distinguish different Lenke types of AIS but rather involve all the cases into one integral analysis, due to the limited number of included studies. This might be potential bias to the outcomes. However, this Bayesian meta-analysis still provided useful information on effectiveness and safety of surgical interventions for treating AIS to the surgeons.

\section{Conclusion}

In summary, this Bayesian meta-analysis demonstrated that PSF had the highest probability to achieve better postsurgical pulmonary function and lower complication rate. Moreover, VAT was believed to have the highest probability to obtain better Cobb angle correction. These results support the current statistics, that more surgeries adopted PSF and less surgeries adopted open anterior approach surgery and thoracoplasty. This analysis also gives a practical recommendation of PSF as a primary surgical treatment for AIS. More research work is required to address the effectiveness and safety of VAT for treating AIS more convincingly. 


\section{Supplementary information}

Supplementary information accompanies this paper at https://doi.org/10. 1186/s12891-020-03233-1.

Additional file 1: Table S1. The Newcastle-Ottawa Scale for assessing the quality of case-controlled studies in meta-analyses.

\section{Abbreviations}

AIS: Adolescent idiopathic scoliosis; 3D: Three-dimensional; ASR + PSF: Combined anterior release and posterior fusion with instrumentation; VAT+PSF: Combined video assisted anterior release and posterior fusion with instrumentation without thoracoplasty; PSF: Posterior fusion with instrumentation without thoracoplasty; AS: Anterior fusion with instrumentation and thoracotomy without thoracoplasty; VAT: Video assisted anterior fusion with instrumentation without thoracoplasty; WT: Any scoliosis surgery with additional thoracoplasty or multiple convex rib resections; FVC: Absolute forced vital capacity; FEV1: Absolute forced expiratory volume in one second; PRISMA: Preferred Reporting Items for Systematic Reviews and Meta-Analyses; OR: Odds ratio; MDs: Mean differences; Cl: Confidence interval; PSRF: Potential scale reduction factor

\section{Acknowledgements}

Not applicable.

\section{Authors' contributions}

L. C., Z. S. and J. H. contributed equally to this work. L. C. and B. L. conceived the design of the study. Z. S. and J. H. collected the data and was involved in design of the study. Y. X. and Z. L. contributed to data analysis and prepared the manuscript. L. C., Q. Z. and B. L. edited the manuscript. All authors have given approval to the final version of the manuscript to be published.

\section{Funding}

The design and data collection of this study were supported by National Natural Science Foundation of China (Grant No. 81960404) and Guizhou Province High-level Overseas Talents Innovation and Entrepreneurship Project (Grant No. (2019) 05). The data analysis of this study was supported by Doctoral Fund of Guizhou Provincial People's Hospital (Grant No. GZSYBS[2017] 04). The interpretation of data and writing of the manuscript were supported by Scientific and Technological Research Project for Traditional Chinese Medicine and Folk Medicine of Guizhou Provincial Administration of Traditional Chinese Medicine (Grant No. QZYY-2018-003).

\section{Availability of data and materials \\ Not applicable.}

\section{Ethics approval and consent to participate}

Not applicable.

\section{Consent for publication}

Not applicable.

\section{Competing interests}

The authors declare that they have no competing interests.

\section{Author details \\ 'Department of Orthopedics, Guizhou Provincial People's Hospital, No.83 Zhongshan East Road, Guiyang 550000, Guizhou, China. ${ }^{2}$ Department of Epidemiology, Johns Hopkins Bloomberg School of Public Health, Baltimore, MD 21205, USA. ${ }^{3}$ Department of Orthopedics, The People's Hospital of Guangxi Zhuang Autonomous Region, Nanning 530021, Guangxi, China.}

Received: 12 December 2019 Accepted: 24 March 2020

Published online: 02 July 2020

\section{References}

1. He C, Wong MS. Spinal flexibility assessment on the patients with adolescent idiopathic scoliosis (AIS): a literature review. Spine. 2018:43(4): E250-8.
2. Chen Z, Rong L. Comparison of combined anterior-posterior approach versus posterior-only approach in treating adolescent idiopathic scoliosis: a meta-analysis. Eur Spine J. 2016;25(2):363-71.

3. Altaf F, Gibson A, Dannawi Z, Noordeen H. Adolescent idiopathic scoliosis. BMJ. 2013;346(f2508):1-7.

4. Tambe A, Panikkar S, Millner P, Tsirikos A. Current concepts in the surgical management of adolescent idiopathic scoliosis. Bone Joint J. 2018;100(4): 415-24.

5. Cheng JC, Castelein RM, Chu WC, Danielsson AJ, Dobbs MB, Grivas TB, Gurnett CA, Luk KD, Moreau A, Newton PO. Adolescent idiopathic scoliosis. Nat Rev Dis Primers. 2015;1:15030.

6. Asher MA, Burton DC. Adolescent idiopathic scoliosis: natural history and long term treatment effects. Scoliosis. 2006;1 (1):2.

7. Weinstein SL, Dolan LA, Cheng JC, Danielsson A, Morcuende JA. Adolescent idiopathic scoliosis. Lancet. 2008:371(9623):1527-37.

8. Hibbs RA. An operation for progressive spinal deformities: a preliminary report of three cases from the service of the orthopaedic hospital. 1911. Clin Orthop Relat Res. 2007;460:17-20.

9. Tambornino JM, Armbrust EN, Moe JH. Harrington instrumentation in correction of scoliosis. A comparison with cast correction. J Bone Joint Surg Am. 1964;46:313-21.

10. Zhou LA, Chen ZB. Luque's operation in spinal surgery. Zhonghua wai ke za zhi. 1987:25(7):394-6 444.

11. Maruyama T, Takeshita K. Surgery for idiopathic scoliosis: currently applied techniques. Clin Med Pediatr. 2009;3:39-44.

12. Harrington PR. Treatment of scoliosis: correction and internal fixation by spine instrumentation. JBJS. 1962;44(4):591-634.

13. Lin Y, Chen W, Chen A, Li F, Xiong W. Anterior versus posterior selective fusion in treating adolescent idiopathic scoliosis: a systematic review and meta-analysis of radiologic parameters. World Neurosurg. 2018;111:e830-44.

14. Dwyer A, Schafer MF. Anterior approach to scoliosis: results of treatment in fifty-one cases. J Bone Joint Surg Br. 1974;56(2):218-24.

15. Lenke LG, Newton PO, Marks MC, Blanke KM, Sides B, Kim YJ, Bridwell KH. Prospective pulmonary function comparison of open versus endoscopic anterior fusion combined with posterior fusion in adolescent idiopathic scoliosis. Spine. 2004:29(18):2055.

16. Lee AC, Feger MA, Singla A, Abel MF. Effect of surgical approach on pulmonary function in adolescent idiopathic scoliosis patients: a systemic review and meta-analysis. Spine. 2016;41(22):E1343-e1355.

17. Franic M, Kujundzic Tiljak M, Pozar M, Romic D, Mimica M, Petrak J, Ivankovic $\mathrm{D}$, Pecina $\mathrm{M}$. Anterior versus posterior approach in $3 \mathrm{D}$ correction of adolescent idiopathic thoracic scoliosis: a meta-analysis. Orthop Traumatol Surg Res. 2012;98(7):795-802.

18. Chen L, Xing F, Xiang Z. Effectiveness and safety of interventions for treating adults with displaced proximal humeral fracture: a network metaanalysis and systematic review. PLoS One. 2016;11(11):e0166801.

19. Hutton B, Salanti G, Caldwell DM, Chaimani A, Schmid CH, Cameron C, loannidis JP, Straus S, Thorlund K, Jansen JP, et al. The PRISMA extension statement for reporting of systematic reviews incorporating network metaanalyses of health care interventions: checklist and explanations. Ann Intern Med. 2015;162(11):777-84.

20. Wells GA, Shea B, O'Connell D, Peterson J, Welch V, Losos M, Tugwell P: The Newcastle-Ottawa Scale (NOS) for assessing the quality of nonrandomised studies in meta-analyses. The Ottawa Hospital Research Institute. Available from: http://www.ohri.ca/programs/clinical_epidemiology/oxford.asp. Accessed 30 June 2020.

21. Brooks SP, Gelman A. General methods for monitoring convergence of iterative simulations. J Comput Graph Stat. 1998;7(4):434-55.

22. Lu G, Ades A. Assessing evidence inconsistency in mixed treatment comparisons. J Am Stat Assoc. 2006;101(474):447-59.

23. Dias $\mathrm{S}$, Welton N, Caldwell D, Ades A. Checking consistency in mixed treatment comparison meta-analysis. Stat Med. 2010;29(7-8):932-44.

24. Unnikrishnan R, Renjitkumar J, Menon VK. Adolescent idiopathic scoliosis: retrospective analysis of 235 surgically treated cases. Indian J Orthop. 2010;44(1):35.

25. Ialenti MN, Lonner BS, Verma K, Dean L, Valdevit A, Errico T. Predicting operative blood loss during spinal fusion for adolescent idiopathic scoliosis. J Pediatr Orthop. 2013;33(4):372-6.

26. Dobbs MB, Lenke LG, Kim YJ, Luhmann SJ, Bridwell KH. Anterior/posterior spinal instrumentation versus posterior instrumentation alone for the treatment of adolescent idiopathic scoliotic curves more than 90 degrees. Spine. 2006;31(20):2386. 
27. Dong Y, Weng X, Zhao H, Zhang J, Shen J, Qiu G. Lenke 5 C curves in adolescent idiopathic scoliosis: anterior vs posterior selective fusion. Neurosurgery. 2016;78(3):324-31.

28. FD F, MC M, PO N, K B, LG L. Perioperative changes in pulmonary function after anterior scoliosis instrumentation: thoracoscopic versus open approaches. Spine. 2005;30(9):1058-63.

29. Franić M, Kovač V. Anterior instrumentation for correction of adolescent thoracic idiopathic scoliosis: historic prospective study. Croatian Med J. 2006:47(2):239.

30. Graham EJ, Lenke LG, Lowe TG, Betz RR, Bridwell KH, Kong Y, Blanke K. Prospective pulmonary function evaluation following open thoracotomy for anterior spinal fusion in adolescent idiopathic scoliosis. Spine. 2000;25(18): 2319.

31. Greggi T, Bakaloudis G, Fusaro I, Di SM, Lolli F, Martikos K, Vommaro F, Barbantibrodano G, Cioni A, Giacomini S. Pulmonary function after thoracoplasty in the surgical treatment of adolescent idiopathic scoliosis. $J$ Spinal Disord Tech. 2010;23(8):e63.

32. Hee HT, Yu ZR, Wong HK. Comparison of segmental pedicle screw instrumentation versus anterior instrumentation in adolescent idiopathic thoracolumbar and lumbar scoliosis. Spine. 2007;32(14):1533.

33. Kim YJ, Lenke LG, Bridwell KH, Cheh G, Sides B, Whorton J. Prospective pulmonary function comparison of anterior spinal fusion in adolescent idiopathic scoliosis: thoracotomy versus thoracoabdominal approach. Spine. 2008;33(10):1055-60

34. Kim YJ, Lenke LG, Bridwell KH, Kim KL, Steger-May K. Pulmonary function in adolescent idiopathic scoliosis relative to the surgical procedure. J Bone Joint Surg (Am Vol). 2005;87(7):1534.

35. Kishan S, Bastrom T, Betz RR, Lenke LG, Lowe TG, Clements D, D'Andrea L, Sucato DJ, Newton PO. Thoracoscopic scoliosis surgery affects pulmonary function less than thoracotomy at 2 years postsurgery. Spine. 2007;32(4): 453-8.

36. Lenke LG, Betz RR, Bridwell KH, Harms J, Clements DH, Lowe TG. Spontaneous lumbar curve coronal correction after selective anterior or posterior thoracic fusion in adolescent idiopathic scoliosis. Spine. 1999; 24(16):1663.

37. Lonner B, Auerbach JM, Milby A, Kean K. Video-assisted thoracoscopic spinal fusion compared with posterior spinal fusion with thoracic pedicle screws for thoracic adolescent idiopathic scoliosis. J Bone Joint Surg (Am Vol). 2009;91(2):398

38. Lonner BS, Kondrachov D, Siddiqi F, Hayes V, Scharf C. Thoracoscopic spinal fusion compared with posterior spinal fusion for the treatment of thoracic adolescent idiopathic scoliosis. Surgical technique. J Bone Joint Surg Am. 2006;88(5):1022

39. Muschik MT, Kimmich H, Demmel T. Comparison of anterior and posterior double-rod instrumentation for thoracic idiopathic scoliosis: results of 141 patients. Eu Spine J. 2006;15(7):1128.

40. Newton PO, Marks MC, Bastrom TP, Betz R, Clements D, Lonner B, Crawford A, Shufflebarger $\mathrm{H}, \mathrm{O}$ 'Brien M, Yaszay B. Surgical treatment of Lenke 1 main thoracic idiopathic scoliosis: results of a prospective, multicenter study. Spine. 2013;38(4):328.

41. Qi Z, Ming L, Gu SX, Zhu XD. Posterior pedicle screw technique alone versus anterior-posterior spinal fusion for severe adolescent idiopathic thoracic scoliosis. J Clin Rehabil Tissue Eng Res. 2009;13(26):5056-61.

42. Qiu Y, Wang WJ, Zhu F, Zhu ZZ, Wang B, Yu Y. Anterior endoscopic release/ posterior spinal instrumentation for severe and rigid thoracic adolescent idiopathic scoliosis. Zhonghua wai ke za zhi. 2011;49(12):1071.

43. Suk SI, Kim JH, Kim SS, Lee JJ, Han YT. Thoracoplasty in thoracic adolescent idiopathic scoliosis. Spine. 2008;33(10):1061.

44. Vedantam R, Lenke LG, Bridwell KH, Haas J, Linville DA. A prospective evaluation of pulmonary function in patients with adolescent idiopathic scoliosis relative to the surgical approach used for spinal arthrodesis. Spine. 2000;25(1):82-90.

45. Verma K, Lonner BS, Kean KE, Dean LE, Valdevit A. Maximal pulmonary recovery after spinal fusion for adolescent idiopathic scoliosis: how do anterior approaches compare? Spine. 2011;36(14):1086.

46. Viola Bullmann TLS, Schmidt C, Gosheger G, Osada N, Liljenqvist UR. Pulmonary function after anterior double thoracotomy approach versus posterior surgery with costectomies in idiopathic thoracic scoliosis. Eur Spine J. 2013;22(2):164-71.
47. Wang Y, Fei Q, Qiu G, Lee Cl, Shen J, Zhang J, Zhao H, Zhao Y, Wang H, Yuan S. Anterior spinal fusion versus posterior spinal fusion for moderate lumbar/thoracolumbar adolescent idiopathic scoliosis: a prospective study. Spine. 2008:33(20):2166.

48. Wong HK, Hee HT, Yu Z, Wong D. Results of thoracoscopic instrumented fusion versus conventional posterior instrumented fusion in adolescent idiopathic scoliosis undergoing selective thoracic fusion. Spine. 2004;29(18): 2031-8 discussion 2039

49. ZC, SY, LL, KQ, LH, GQ, LT, ZJ. Convex short length rib resection in thoracic adolescent idiopathic scoliosis. J Pediatr Orthop. 2011;31(7):757-63.

50. Zhan SQ, Chang YB, Zeng SX, Wang YS, Ke YH, Ma YC. Comparison of surgical treatment in single thoracolumbar-lumbar adolescent idiopathic scoliosis: anterior versus posterior surgery. Zhonghua wai ke za zhi. 2010; 48(6):419.

51. Zhang H, Wang Y, Guo C, Tang M, Chen L, Liu S, Wang Y, Chen J. Posterioronly surgery with strong halo-femoral traction for the treatment of adolescent idiopathic scoliotic curves more than $100^{\circ}$. Int Orthop. 2011; 35(7):1037-42.

52. Zhang HQ, Gao QL, Lei GE, Jian-Huang WU, Liu JY, Guo CF, Liu SH, Shi-Jin LU, Jin-Song LI, Yin XH. Strong halo-femoral traction with wide posterior spinal release and three dimensional spinal correction for the treatment of severe adolescent idiopathic scoliosis. 中华医学杂志 (英文版). 2012;125(7): 1297-302.

53. Yaszay B, Bastrom TP, Bartley CE, Parent S, Newton PO. The effects of the three-dimensional deformity of adolescent idiopathic scoliosis on pulmonary function. Eur Spine J. 2017;26(6):1658-64.

54. Lonner BS, Ren Y, Yaszay B, Cahill PJ, Shah SA, Betz RR, Samdani AF, Shufflebarger HL, Newton PO. Evolution of surgery for adolescent idiopathic scoliosis over 20 years: have outcomes improved? Spine. 2018;43(6):402-10.

55. Cahill PJ, Pahys JM, Asghar J, Yaszay B, Marks MC, Bastrom TP, Lonner BS, Shah SA, Shufflebarger HL, Newton PO, et al. The effect of surgeon experience on outcomes of surgery for adolescent idiopathic scoliosis. $J$ Bone Joint Surg Am. 2014;96(16):1333-9.

56. Luo M, Wang W, Shen M, Xia L. Anterior versus posterior approach in Lenke 5C adolescent idiopathic scoliosis: a meta-analysis of fusion segments and radiological outcomes. J Orthop Surg Res. 2016;11(1):1-8.

57. Padhye K, Soroceanu A, Russell D, El-Hawary R. Thoracoscopic anterior instrumentation and fusion as a treatment for adolescent idiopathic scoliosis: a systematic review of the literature. Spine Deformity. 2018;6(4): 384-90.

58. de Kleuver M, Lewis SJ, Germscheid NM, Kamper SJ, Alanay A, Berven SH, Cheung KM, Ito M, Lenke LG, Polly DW, et al. Optimal surgical care for adolescent idiopathic scoliosis: an international consensus. Eur Spine J. 2014;23(12):2603-18.

\section{Publisher's Note}

Springer Nature remains neutral with regard to jurisdictional claims in published maps and institutional affiliations.
Ready to submit your research? Choose BMC and benefit from:
- fast, convenient online submission
- thorough peer review by experienced researchers in your field
- rapid publication on acceptance
- support for research data, including large and complex data types
- gold Open Access which fosters wider collaboration and increased citations
- maximum visibility for your research: over $100 \mathrm{M}$ website views per year
At BMC, research is always in progress.
Learn more biomedcentral.com/submissions 